Penultimate version, March 2016; final version appeared in

Von Rang und Namen - Philosophical Essays in Honour of Wolfgang Spohn,

eds. W. Freitag, H. Rott, H. Sturm and A. Zinke,

Münster: Mentis 2016, pp. 379-399.

\title{
»If Oswald had not killed Kennedy«: Spohn on counterfactuals
}

\author{
Hans Rott
}

\begin{abstract}
Wolfgang Spohn's theory of ranking functions is an elegant and powerful theory of the structure and dynamics of doxastic states. In two recent papers, Spohn has applied it to the analysis of conditionals, claiming to have presented a unified account of indicative and subjunctive (counterfactual) conditionals. I argue that his analysis fails to account for counterfactuals that refer to indirect causes. The strategy of taking the transitive closure that Spohn employs in the theory of causation is not available for counterfactuals. I have a close look at Spohn's treatment of the famous Oswald-Kennedy case in order to illustrate my points. I sketch an alternative view that seems to avoid the problems.
\end{abstract}

Keywords: Conditionals, counterfactuals, indicative conditionals, subjunctive conditionals, ranking theory, Spohn

\section{Introduction}

It must have been around 1981 when I heard Wolfgang Spohn give a seminar talk on the dialectics between spurious and hidden causes at LMU Munich. I still remember vividly that it was one of the two magic moments of my student times. (The other one was Ulrich Blau's talk on the hangman and the liar paradoxes. Both papers were published in a voluminous Erkenntnis special issue that was at the same time a Festschrift devoted to Wolfgang Stegmüller's 60th birthday). This kind of philosophy was exactly what I wanted to do! In the acedemic year 1981/82 I attended Wolfgang's class Der Kausalitätsbegriff aus analytischer Sicht in which he started developing his own theory of causation. My intellectual development would most likely have taken a very different course if I had not learned so much from Wolfgang Spohn, first as his student and later as his peer.

Spohn's theory of ranking functions saw the light of day in his seminal paper $\gg$ Ordinal Conditional Functions: A Dynamic Theory of Epistemic States« (1988). This publication immediately placed its author into the top ranks of what is today called »formal epistemology «. The development of the theory culminated in his magisterial book The Laws of Belief: Ranking Theory and Its Philosophical Applications, published by Oxford University Press in 2012. Spohn's theory has been uniquely successful not only among philosophers and logicians, but also among people working in knowledge representation within artificial intelligence research. There were predecessors-George L.S. Shackle, Nicholas Rescher and L. Jonathan Cohen-and researchers working in parallel—Didier Dubois and Henri Prade—but the theory is entirely Spohn's own creation 1 The formal representation of belief and degrees of belief

\footnotetext{
${ }^{1}$ Even though the now-current name of the theory is due to Goldszmidt and Pearl (1992).
} 
has been a contested area between logic and probability theory for centuries. Spohn has established, conclusively to my mind, that there is an important level of representation that lies »between« purely qualitative-relational and quantitative-probabilistic approaches, combines the advantages of both and obeys beautiful laws of its own. Any discussion that logicians and Bayesians might have today about the question of how to best represent states of rational belief and their dynamics is incomplete if it fails to take into consideration how the question is answered within the theory of ranking functions.

In two recent weighty papers, Spohn $(2013 ; 2015)$ has applied his ranking theory to the analysis of conditionals ${ }^{2}$ Aiming at a unified theory of conditionals covering both the indicative and the subjunctive variety, Spohn attempts »to demonstrate a unified expressionist framework for interpreting our rich assertive conditional idiom « and to offer »rich interpretive options within the unified scheme « by »providing various expressive alternatives to the Ramsey test « (p. 1103). Spohn writes:

$[R]$ anking theory is well suited for a comprehensive and unified account of conditionals. The basic reason for being so suited can be summarised in one sentence: conditionals of all kinds express our conditional beliefs or something about them, and our conditional beliefs are most adequately represented by ranking theory. (p. 1)

Spohn's papers highlight two fundamental distinctions that are relevant for the understanding of the difference between indicative and subjunctive conditionals:

- conditionals as propositional vs. non-propositional

- conditionals as encoding reasons vs. as encoding causes

Spohn claims that the full ranking-theoretic apparatus is needed for a proper analysis of the two distinctions. He maintains that indicatives are non-propositional; they express reason relations captured by the Ramsey test, which in turn refers to conditional beliefs that have no truth conditions. Subjunctives, in contrast, are said to represent propositions about causal relations and thus have truth conditions. ${ }^{3} \mathrm{He}$ argues for the latter claim in two steps. First, he suggests that »[many, if not] most counterfactuals are to be interpreted in a causal way « (p. 1098/20, the phrase in square brackets appears on p. 1098 only). And second, in a »big claim«, he maintains that »all causal conditionals instantiate scheme (VI) in a specific[,] context-independent way « (p. 1097/20, original emphasis). Scheme (VI) is never explicitly formulated. Spohn gives us one particular instance of it, viz., the scheme for the positively relevantist »circumstances-are-such-that reading « of a conditional If $A$, then $B$ based on a given partition $\mathcal{P}$ of the possibility space $W$ (p. 1096/18):

\footnotetext{
${ }^{2}$ In the following, many page numbers are given without further specification. High numbers refer to Spohn (2013), low numbers to Spohn (2015). Since the two papers overlap to some extent, I frequently use the format $>\mathrm{p}$. high number/low number to refer to both papers simultaneously.

${ }^{3}$ Spohn (p. 1102/23 and p. 25) indicates that subjunctives in addition express conditional beliefs. Cf. the remarks on page 8 below.
} 
(VI.1)

$$
\tau\left(C^{*}\right)>0, \text { where } C^{*}=\bigcup\{C \in \mathcal{P}: \tau(B \mid A \cap C)>\tau(B \mid \bar{A} \cap C)]^{4}
$$

Evidently, this condition requires explanation. I hope that it, or something very much like it, will become comprehensible in the course of this paper.

In Spohn's theory, causes are reasons given some background context or »circumstances«. Since causes and effects have fixed temporal locations, the antecedents and consequents of causal conditionals are supposed to refer to fixed temporal locations. We will assume that their negations refer to the same locations.

\section{Spohn on the Oswald-Kennedy case}

\subsection{The Oswald-Kennedy case, indicatives and subjunctives}

In order to obtain corroboration for his theory of conditionals, Spohn (pp. 1101-1103/ 22-24) analyses the widely discussed example of Ernest Adams (1970, p. 90). It involves two conditionals about the assassination of John F. Kennedy in Dallas at 12:30 p.m. on 22 November 1963.

(1) If Oswald did not kill Kennedy, someone else did.

(2) If Oswald had not killed Kennedy, no one else would have.

Spohn adds to sentence (2), in parentheses, »and Kennedy would have been alive, for a while [at least]«. This appendage will be neglected here. I also neglect two differences between Spohn's example and the original one of Adams, who contrasted If Oswald didn't shoot Kennedy in Dallas, then no one else did with If Oswald hadn't shot Kennedy in Dallas, then no one else would have. First, Adams presented a minimal pair where the »unjustified « indicative and the »justified « subjunctive conditional differ only in the verb phrases of the antecedent and the consequent, thus avoiding the question what role exactly negation is playing in (1) and (2). Second, Adams's example differs from Spohn's in having then at the beginning of each main clause $5^{5}$

Spohn takes it to be obvious that both of these conditionals are »true or at least clearly acceptable« (p. 1101/23). Let $O$ be the sentence Oswald killed Kennedy and $S$ be the sentence Someone else killed Kennedy. Where convenient, we let $O$ and $S$ denote the propositions represented by these sentences. According to Spohn (p. $1102 / 23$ ) »it is clear that we believe $O$ and reject $S$.«I used to think that the indicative (1) is an »open conditional « and cannot be acceptable if $O$ is believed, but I have realised that uttering (1) after saying I believe that Oswald killed Kennedy is perfectly possible, especially if (1) is prefixed by But and the if in (1) is emphasised 6

\footnotetext{
${ }^{4}\left(\right.$ VI.2) and (VI.3) replace the symbol $>><$ in the definition of $C^{*}$ by $>=<$ and $><<$, respectively. Somewhat deviating from his big claim, Spohn actually employs (VII.1), a special case of the non-relevantist scheme $(\mathrm{V})$, rather than the relevantist (VI) for the analysis of the Oswald-Kennedy case. See page 4 below.

${ }^{5}$ This is quite surprising, considering what will be said in footnote 14 below (cf. Iatridou 1994).- - I finally neglect the fact that both Adams's to shoot and Spohn's to kill are causative verbs meaning to cause to die (with a bullet or arrow), and causing-to-die may be difficult to enter as a relatum into a causal relation potentially represented by a conditional.

${ }^{6}$ In contrast, uttering (1) after saying I know that Oswald killed Kennedy is bad English and perhaps »ungrammatical .
} 
Throughout this paper, I will follow Spohn in taking for granted that we believe $O$, reject $S$ and accept both (1) and (2). Let us pretend to be Warrenites who believe that Oswald was a lone gunman and no one else was involved in the killing of Kennedy 7

The Oswald-Kennedy example has usually been taken as conclusive evidence that indicatives and subjunctives »are indeed logically distinct species« (Adams 1970, p. 89) and that they »really are two different sorts of conditional« (Lewis 1973b, p. 3). In their twin articles, Gillies (2012, p. 449) and von Fintel (2012, p. 466) maintain that indicative conditionals »stand apart from [...] subjunctive or counterfactual conditionals « and that indicatives and subjunctives/counterfactuals are »two main kinds of conditionals [...that] clearly [...] differ in meaning «, respectively. So I think it is fair to say that the segregative view expressed by Adams and Lewis is still very influential, if not the dominant one.

However, as many people have noted, this view is not completely satisfying. A good compositional analysis of conditionals would explain differences by differences and commonalities by commonalities. In particular, it would explain the difference in meaning between (1) and (2) with reference to the difference in sentence moods, and identify some commonality in meaning that corresponds to the syntactical fact that both (1) and (2) exhibit a conditional structure marked by the word if. Acknowledging earlier attempts to »preserve unity« by Stalnaker (1975), Edgington (1995, p. 315 ; 2008, pp. 4-6) and Bennett (2003):8 Spohn offers a unifying perspective on both indicative and subjunctive conditionals. He claims to have

... a perfectly straightforward account of this example within my [rankingtheoretic] framework, which neither involves context shift nor different theories of conditionals, but only one ranking function and two expressive options. (p. 1101-1102/23)

In order to keep things simple (p. 1102/23), Spohn disregards relevance considerations in his analysis of the Oswald-Kennedy case, and I will follow him in that. Thus it will not be assumed that the antecedents of the conditionals are positively relevant to their consequents, but rather that they contribute (in specific ways) to the conditional belief that the respective consequents are true.

\subsection{Spohn's ranking-theoretic modelling of the Oswald-Kennedy case}

Spohn uses two-sided conditional ranking functions $\tau$ for his analysis of conditionals. For two-sided ranking functions, the value of $\tau(B \mid A)$ is positive iff $B$ is believed given

\footnotetext{
${ }^{7}$ The Warrenite view is not necessary for the acceptance of both (1) and (2) because such acceptance is compatible with the belief that there were multiple assassins each of whom fired a lethal shot but who would only have struck together. But the Warrenite view is the background against which Adams's example is usually discussed, and evidently it is the background of Spohn's reasoning, too. Without pretense, however, I find it very probable that Warrenites are wrong. See, e.g., McKnight (2005) and Douglass (2008) for good accounts of the evidence casting doubt on the lone-gunman theory. Americans have always been skeptical about the report of the Warren Commission. In polls conducted by Gallup over the last 50 years, it was found that only 10-36\% of Americans believed a single man (Oswald) was responsible for the shooting and $50-81 \%$ believed that others were involved in a conspiracy.

${ }^{8}$ Stalnaker is mentioned on p. 1101/23, Bennett and Edgington only on p. 1101 (there is a typo regarding Edgington's 1995 page number).
} 
$A$, negative iff $B$ is rejected given $A$, and equal to zero iff $B$ is neither believed nor rejected given $A$ (p. 1086/10). Spohn suggests interpreting the indicative conditional (1) according to his rendering of the Ramsey test (p. 1102/23):

(3) $\tau(S \mid \bar{O})>0$

This expresses a conditional belief in $S$ given $\bar{O}$, which is logically stronger than the unconditional belief in the corresponding material conditional $\bar{O} \supset S$. The latter would mean that $\tau(O \cup S)>0$ which already follows from our believing $O 9$

The counterfactual conditional, in contrast, is interpreted by Spohn (p. 1102/23) as expressing

(4) $\tau\left(H^{*}\right)>0$ and $\tau\left(\bar{S} \mid \bar{O} \cap H^{*}\right)>0$

Condition (4) has two parts. First, it expresses an unconditional belief in a proposition $H^{*}$, and second, it expresses a conditional belief that is like a negation of (3), except that the relevant condition is not just $\bar{O}$ but $\bar{O} \cap H^{*}$. Obviously, it is of crucial importance what the content of the proposition $H^{*}$ is. Things are getting a little complicated now. Here is Spohn's (p. 1100/22) definition, as adapted to the present example:

(5) $H^{*}=\left\{w \in W: \tau\left(\overline{S_{t^{\prime}}} \mid \overline{O_{t}} \cap H_{w, t^{\prime}}^{t}\right)>0\right\}$

We need to unravel this further. Spohn presents the subjunctive conditional (2) in the context of his discussion of causal conditionals. He assumes that the antecedent and the consequent of a causal counterfactual represent »simple propositions « (p. 1098/20) referring to fixed temporal locations $t$ and $t^{\prime}$, respectively, with $t^{\prime}$ being later than $t$. This is why we write $\overline{O_{t}}$ and $\overline{S_{t^{\prime}}}$ rather than just $\bar{O}$ and $\bar{S}$ in (5). Unfortunately Spohn is silent on the temporal locations involved in the Oswald-Kennedy case, but I think we may assume that the »non-actions « (omissions) $\bar{O}$ and $\bar{S}$ have the same temporal locations as the actions $O$ and $S{ }^{10}$ The set $H_{w, t^{\prime}}^{t}$ denotes the history or the course of events in the possible world $w$ up to time $t^{\prime}$ with the exception of the event(s) happening at $t$ (p. 1099/21). Notice in particular that the proposition $H_{w, t^{\prime}}^{t}$ contains information not only about the past of the antecedent event, but also all information about the happenings between the antecedent event and the consequent event.

The interpretation of $H^{*}$ is not easy. A world $w$ belongs to the proposition $H^{*}$ if and only if it is such that the agent conditionally believes that no one else kills Kennedy at $t^{\prime}$ given Oswald's not killing Kennedy at $t$ and $w^{\prime}$ 's history up to $t^{\prime}$ with a gap at $t$.

\footnotetext{
${ }^{9}$ Notice also that a belief conditional on $\bar{O}$ is different from a belief after some conditionalisation by $\bar{O}$. For the process of conditionalisation, Spohn's model requires specifying an input parameter, a natural number $n$, that represents the strength with which $\bar{O}$ is to be believed in the posterior belief state. Incidentally, I raised an objection in Rott 2014 240-241) against the fact that the meaning of $n$ is dependent on the ranking function that represents the agent's doxastic state (the representation relation is many-one). I tentatively suggested that it might help to normalise one-sided ranking functions in such a way that they assume as values real numbers between 0 and 1 rather than natural numbers of arbitrary magnitude. In the meantime I have realised that the normalisation function that I had in mind (with corresponding changes in the conditionalisation process) is essentially the same as the one given by Dubois and Prade (1991, p. 236-237) twenty-five years ago, and that it does not solve the problem I had hoped it solves.

${ }^{10}$ So we would also be justified in using the notation $» \bar{O}_{t} \ll$ and $» \bar{S}_{t^{\prime}} \ll$.
} 
Notice that $H^{*}$ is doubly relative; it depends not only on the agent's conditional beliefs as encoded by the ranking function $\tau$, but also on the specific antecedent and consequent at issue (here, $\bar{O}_{t}$ and $\bar{S}_{t^{\prime}}$ ). Spohn describes $H^{*}$ as representing »our historical belief « (p. 23) or simply »history « ${ }^{11}$ I feel that these labels are somewhat misleading. The proposition $H^{*}$ certainly does not encode the history of the effect with the exception of the cause. The history of the actual world $w @$ in this sense is $H_{w_{\circledast}, t^{\prime}}^{t}$, not $H^{*}$. $H^{*}$ is the set of worlds the history of which before $t^{\prime}$, taken together with Oswald's not killing Kennedy at $t$, is a sufficient condition for the agent to believe that no one else killed Kennedy at $t^{\prime}$. The set $H^{*}$ contains countless possible worlds with wildly differing histories - thus also wildly differing from the history of the actual world. For instance, a world in which Kennedy was assassinated by Thomas Vallee in Chicago on 2 November 1963, qualifies for inclusion in $H^{*}$, because there would be no killing at any later time $t^{\prime}$. But we believe and know that Vallee did not kill Kennedy. Perhaps one can call $H^{*}$ a lone-gunman proposition. In any case, we will see in the next section that employing $H^{*}$-or $H_{w_{\circledast}, t^{\prime}}^{t}$ for that matter-in the evaluation of counterfactuals is problematic. I will argue that we actually do not take our world to be in $H^{*}$.

\subsection{A Warrenite's belief state}

Spohn offers a concrete representation of a belief state in order to show that he is able to handle the Oswald-Kennedy case adequately. He suggests that our doxastic state (p. 1102/23) — which is, as we agreed to pretend, a Warrenite's doxastic state—can be represented by the $\tau$ function given in Table $11^{12}$ This ranking function delivers what

\begin{tabular}{c|c|c|c|c}
$\tau$ & $O \cap S$ & $O \cap \bar{S}$ & $\bar{O} \cap S$ & $\bar{O} \cap \bar{S}$ \\
\hline$H^{*}$ & -2 & 1 & -6 & -4 \\
\hline$\overline{H^{*}}$ & -1 & -2 & -3 & -4
\end{tabular}

Table 1: A Warrenite's ranking function, according to Spohn

Spohn wants, namely both $\tau(S \mid \bar{O})>0$ and $\tau\left(H^{*}\right)>0 \& \tau\left(\bar{S} \mid \bar{O} \cap H^{*}\right)>0$. There are a few things that strike me as strange about this $\tau$ function. First, it is intuitively unclear how strongly believed Spohn's lone-gunman proposition $H^{*}$ is as compared to the propositions composed of $O$ and $S$. On the one hand, $H^{*}$ seems to be very strongly endorsed, since the proposition $\bar{O} \cap S \cap H^{*}$, i.e., that someone other than Oswald killed Kennedy within $H^{*}$, is even more strongly disbelieved than $\bar{O} \cap \bar{S}$, i.e., that Kennedy was not killed at all. On the other hand, it seems to be rather weakly endorsed, since $O \cap S \cap H^{*}$, i.e., that Oswald and someone else took a shot at Kennedy even within $H^{*}$, is comparatively mildly disbelieved. My intuitions are feeble here, I find it hard to get a proper grasp on this ranking function. The difficulty may be due to the open questions whether $O$ and $\bar{S}$ are supposed to be simultaneous and whether they may be

\footnotetext{
${ }^{11}$ See his formulations »history is such $\left(=H^{*}\right)$ that, if $\bar{O}$ and $H^{*}$, then $\bar{S} \ll\left(\right.$ p. 1102) and $»$ history $\left(=H^{*}\right)$ is such that, if $\bar{O}$ and $H^{*}$, then $\bar{S} \ll($ p. 23).

${ }^{12}$ Spohn (p. 1102/23) gives the representation in terms of a (one-sided) negative ranking function $\kappa$ which specifies degrees of implausibility of the relevant propositions. For the sake of continuity, I keep on using two-sided $\tau$ functions here. The two representations are equivalent, either kind of function can be obtained from the other: $\tau(A)=\kappa(\bar{A})-\kappa(A)($ p. 1086/10) and $\kappa(A)=\max (0,-\tau(A))$
} 
suitably linked by a causal relation. It may also be due to the problem that the content of $H^{*}$ is hard to understand (recall that its definition refers to $\tau, O$ and $S$ ), and that the use of $H^{*}$ will indeed turn out to be problematic in the next section. I do not want to speculate further about the interaction of $H^{*}$ with Boolean compounds of $O$ and $S$.

Can we say anything about what a Warrenite's doxastic state concerning the Oswald-Kennedy case should look like? We may take it to be very sure that Kennedy was killed by someone in Dallas at 12:30 p.m. on 22 November 1963. Although a conspiracy might possibly have included killing a look-alike of Kennedy, this is a very remote possibility that has, to the best of my knowledge, not been seriously considered by anyone. The events preceding and following the assassination proved with as much certainty as we can ever get in empirical matters that Kennedy was in fact shot. As pretended Warrenites, moreover, we are quite sure that Oswald was the shooter, we find the idea that there were other snipers besides Oswald very implausible, and we find even more implausible the idea that there were other snipers, but Oswald did not take a shot. This is, it seems to me, about as much as we can confidently say.

\section{Problems with Spohn's modelling of the Oswald-Kennedy counterfactual}

\subsection{Four problems: causal connections, temporal locations, conditional beliefs and abrupt changes}

I believe that there are a number of problems in Spohn's presentation of the OswaldKennedy case. First, it is unclear whether (2) is a causal conditional at all. Spohn says that $\gg[\mathrm{w}]$ hen I utter the counterfactual if $A_{t}$ had not been the case, $B_{t^{\prime}}$ would not have been the case, intending a causal interpretation, I express my belief that $A_{t}$ is a (direct) cause of $B_{t^{\prime}}$ « (p. 1100, very similarly on p. 22) But provided that we admit the metaphysical possibility of several persons killing someone ${ }^{13}$ it seems odd to say that Oswald's killing of Kennedy was a (direct) cause of no one else's killing him. According to the Warrenite story, no one else was around prepared to kill Kennedy in the first place. It is odder still to say - and this is what Spohn's gloss would requirethat Oswald's killing of Kennedy was a (direct) cause of someone else's killing him. Warrenites deny that someone else than Oswald killed Kennedy, so someone else's killing Kennedy cannot be the effect of anything 14

Second, Spohn does not explicitly specify the temporal locations referred to by the antecedent and the consequent of (2). The antecedent time is easy to determine, it is 12:30 p.m. on 22 November 1963 (we need not be more precise here). But the consequent time is less well-defined. On the most plausible construal of the case, we

\footnotetext{
${ }^{13}$ Read individually, not collectively. For such cases of overdetermination it is not necessary that the several snipers fire their shots at exactly the same time. A shot fired a little later my lead to death more rapidly.

${ }^{14}$ This reveals that from the point of view of a Warrenite, (2) is an even if type conditional. A Warrenite could equally well say Even if Oswald had not killed Kennedy, no one else would have killed him. Regardless of whether Oswald killed Kennedy or not, there is not, and would not be, any other assassin. That Oswald shot Kennedy is irrelevant to the proposition that no one other than Oswald shot Kennedy, and that latter proposition is counterfactually independent of Oswald's shooting Kennedy. It is an unwelcome complication of this example that the counterfactual (2) turns out to be of a strikingly non-paradigmatic type. Variants of even if type conditionals were called »semifactuals « by Goodman (1954), »unconditionals « by Rott (1986) and »non-interference conditionals« by Bennett (2003) who takes up a term of Reichenbach (1954).
} 
are interested in whether someone else shot Kennedy at the same time. This would make the consequent time $t^{\prime}$ identical to the antecedent time $t$. But Spohn requires causes to precede their effects. So for this reason, too, the suggestion that (2) is a causal conditional seems problematic.

Let us have a short look at the other possibilities regarding the time of the consequent. The consequent of the counterfactual (2), as uttered in ordinary language, does not even preclude reference to a time $t^{\prime}$ earlier than the antecedent time $t$. If some other assassin had preempted Oswald's killing, this would have been sufficient to make (2) false. But again, this case would not conform to Spohn's idea that the counterfactual represents a causal relation. If $t^{\prime}$ is later that $t$, on the other hand, then we are likely to run into the problems I am going to describe in the next section, in the discussion of the pair (6) and (7). In any case, the temporal location of the consequent of (2) has to be discussed in order to understand this counterfactual's meaning.

The first two problems have concerned the particular example of Kennedy and Oswald, but there are also questions about the general idea of Spohn's definition. The third problem concerns a minor point that would probably just need some elucidation. We have already mentioned that Spohn neglects the relevance idea in his analysis of the Oswald-Kennedy case for the sake of simplicity, and there is nothing objectionable about that. So Spohn (pp. 1100/22 and 1102/23) says that counterfactuals should be interpreted according to the scheme

(VII.1) $\tau\left(H^{*}\right)>0$, where $H^{*}=\left\{w \in W: \tau\left(B_{t^{\prime}} \mid A_{t} \cap H_{w, t^{\prime}}^{t}\right)>0\right\}$.

But this scheme mentions only the unconditional belief that $H^{*}$ is true, and does not feature an analogue of the second part of (4) that specifies the conditional belief of $\bar{S}$ given $\bar{O} \cap H^{*}$. Why does Spohn insist in (4) that the counterfactual (2) expresses both an unconditional, truth-evaluable belief and a conditional belief that is not truthevaluable? I have not found any reasons motivating the second part of (4).

Fourth, Spohn changes the history of the effect just with respect to a single isolated fact at $t$, the temporal location referred to by the antecedent. We may ask whether it really makes sense to do so. Wouldn't it be better to change also the temporal »surroundings « of $t$ if we mentally perform an intervention at $t$ ? Otherwise the hypothesised event at $t$ that does not belong to the actual history of the world might seem to present us with an inexplicable miracle. Suppose that Oswald had not killed Kennedy at $t$. Would we not expect that some earlier events have to be different in order to make this a realistic supposition? Perhaps Oswald never started planning for the assassination. Perhaps he experienced a flash of inspiration that what he set out to do was wrong. Perhaps some noise distracted him so that he missed his target. In any case, it seems that changes at $t$ need to be »prepared « by some gentle changes in the immediate past of $t$ in order to avoid unnatural leaps in the course of events. This should be true for Spohn's discrete time model, but problems get a lot worse if we take seriously the idea that time is continuous. If everything develops smoothly in accordance with the natural laws before $t$ and between $t$ and $t^{\prime}$, how should it be understood that just at this single, isolated point of time $t$ some event is deviant, a misfit as it were, but is still capable of producing an effect at some later, possibly distant point of time $t^{\prime}$ ? Such an abrupt happening of a causally efficacious event must either appear to be miraculous or the result of some irreducibly indeterministic event. 


\subsection{The fifth problem: retrodicting antecedent-time events}

The fifth point is the biggest and most important one. Spohn bases his analysis of subjunctive or counterfactual conditionals on his earlier analysis of direct causation. Proposition $A$ is a direct cause of proposition $B$ if the causal path leading from $A$ to $B$ is not $»$ mediated by further facts« (Spohn 1983, p. 386) or »contains no mediating steps « (Spohn 2012, p. 356) ${ }^{15}$ But why should we restrict attention to direct causes in the evaluation of counterfactuals? Why should we not be ready to consider indirect causes as well? Just as a because clause may mention any — direct or indirect—cause, a counterfactual if clause is suitable to refer to any-direct or indirect-cause ${ }^{16}$ Spohn says that the counterfactual If $\phi$ had not been the case, $\psi$ would not have been the case, with $\phi$ representing a simple proposition $A_{t}$ and $\psi$ representing a simple proposition $B_{t^{\prime}}$, expresses the speaker's belief that $A_{t}$ is a (direct) cause of $B_{t^{\prime}}$ (p. 1100/22). Both in Spohn (2013) and in Spohn (2015), he puts »direct « in parentheses three times, without any further explanation how this parenthetical insertion is to be read. We will now show that the neglect of indirect causes has rather devastating consequences for his account of subjunctive conditionals.

I would like to illustrate the problem with the help of the Oswald-Kennedy example again. In order to have a counterfactual that is clearly causal and has definite temporal locations of its antecedent and consequent, let us now consider the following variant of the example used by Adams and Spohn.

(6) If Oswald did not kill Kennedy, the Warren Commission was established on 29 November 1963.

(7) If Oswald had not killed Kennedy, the Warren Commission would not have been established on 29 November 1963.

While (6) certainly sounds odd, one can hardly call it false. It is a known fact that Johnson established the Warren Commission on 29 November 1963, and this is so irrespective of whether Oswald killed Kennedy or not ${ }^{17}$ But I am mainly interested now in the counterfactual (7) which is clearly acceptable to anyone who is convinced that Oswald was a lone assassin. Oswald's killing of Kennedy was a cause of the establishment of the Warren Commission.

Now let us see how Spohn's recipe in (4) and (5) handles (7). First, we notice that there is sufficient time for many important events to happen in the interval between the

\footnotetext{
${ }^{15}$ The official, rather formal definitions are Definition (10) in Spohn (1983. p. 388) and Definition 14.3 in Spohn (2012 p. 356).

${ }^{16}$ The relation between counterfactuals and because sentences is itself controversial. Spohn (p. $1100 / 22$ ) suggests, somewhat casually, that $B_{t^{\prime}}$ because $A_{t}$ is equivalent to If $A_{t}$ had not been the case then $B_{t^{\prime}}$ would not have been the case. Spohn thus essentially agrees with Ryle (1950, p. 339-340), and may draw support from Hume (1756 p. 76) and Lewis (1973a p. 563). But opinions are divided on whether this idea is a good one. Its formulation, inserted only into the 1756 edition of the first Enquiry, remains strangely isolated in Hume's work. Ryle does not elaborate on his observation. And Lewis modified it in his later paper on causation (Lewis 2004). In Rott (1986), I worked out the idea that a conditional's antecedent should be relevant for its consequent and concluded that the factual $B_{t^{\prime}}$ because $A_{t}$ is equivalent to its backtracking counterfactual »contraposition «If $B_{t^{\prime}}$ had not been the case then $A_{t}$ would not have been the case. In effect, I sided with Goodman (1954, p. 14) and McCall (1983, pp. 318-320), against Ryle.

${ }^{17}$ Sentence (6) is an even if type of conditional. Cf. footnote 14 above.
} 
antecedent time $t$ and the consequent time $t^{\prime}$. Just after 12:30 p.m. on 22 November 1963, Kennedy was brought to Parkland Hospital, Dallas, where he was pronounced dead by the doctors at 1:00 p.m. Acting White House press secretary Kilduff officially announced Kennedy's death at about 1:30 p.m. At about 2:00 p.m., his body was removed and driven to Air Force One. At about 2:15 p.m., doctors Perry and Clark held a press conference at Parkland Hospital on the wounds of the president. Johnson was sworn in as President of the United States aboard Air Force One at about 2:30 p.m. The autopsy was performed at Bethesda Naval Hospital from about 8:00 p.m. to 12:30 a.m. on 23 November 1963. On 25 November 1963, Kennedy was buried at Arlington National Cemetery. The assassination was reported almost immediately after it happened by local and nationwide radio stations, and about two hours later by television networks. The actual history $H_{w_{\circledast}, t^{\prime}}^{t}$, where $t$ is the time of the assassination and $t^{\prime}$ is the time of the establishment of the Warren Commission, includes all these events in the immediate aftermath of the assassination. That Kennedy was assassinated at time $t$ can be perfectly retrodicted from these events. Believing or assuming that they happened leads one to believe or assume that Kennedy was killed by someone at $t$, and offers no reason to believe or assume that Johnson would have refrained from establishing of the Warren Commission at $t^{\prime}$. Adding the assumption that it was not Oswald who shot Kennedy is irrelevant here. But this means that $\tau\left(W_{t^{\prime}} \mid \overline{O_{t}} \cap H_{w_{\circledast}, t^{\prime}}^{t}\right)>0$ and thus $\tau\left(\overline{W_{t^{\prime}}} \mid \overline{O_{t}} \cap H_{w_{\Theta} t^{\prime}}^{t}\right)<0$ (where $W_{t^{\prime}}$ stands for the sentence The Warren Commission was established on 29 November 1963). Thus the actual world w@ is not in $H^{*}$. What is more, every person minimally informed about the happenings in November 1963 knows this and thus has $\tau\left(\overline{H^{*}}\right)>0$, or equivalently, $\tau\left(H^{*}\right)<0$. But Spohn requires (7) to express $\tau\left(H^{*}\right)>0$. Consequently, according to his interpretation of counterfactuals, no minimally informed person should have accepted the counterfactual (7) ${ }^{18}$

So we have found a perfectly acceptable conditional that does not fulfil Spohn's conditions (4) and (5). Spohn's conditions are too narrow. There must be a mistake somewhere. The mistake, I submit, lies in the fact that the historical proposition $H_{w, t^{\prime}}^{t}$, which is used as a condition in (5), includes all the events happening between the antecedent time $t$ and the consequent time $t^{\prime}$. This fifth problem is a rather severe one, for similar examples are not hard to come by.

\subsection{Direct causes, indirect causes and the issue of transitivity}

Why does Spohn insist on conditionalising on $H_{w, t^{\prime}}^{t}$ ? I believe that this idea is inherited from his theory of causation that starts with a definition of direct causation. Based on a sophisticated dialectics between »spurious« and »hidden« causes, Spohn (1983, p. $385-388$; 2012, pp. 358-360) argues that everything happening between $t$ and $t^{\prime}$ must be included in the »obtaining circumstances « of a direct cause-effect relationship.

This argument is powerful in Spohn's theory-building enterprise, but it does not transfer to the analysis of counterfactuals as used in natural language. As we have just

\footnotetext{
${ }^{18} \mathrm{I}$ have chosen (7) so that there is a sizeable interval between $t$ and $t^{\prime}$. But even if the consequent time $t^{\prime}$ is chosen just a little bit later than the antecedent time $t$, the situation does not change much. By watching the Zapruder film, say, it is clear that what happened very shortly after the shooting contained rather conclusive evidence that Kennedy was in fact shot dead. According to the recipe of (4) and (5), Warrenites should not accept If Oswald had not shot Kennedy, agent Hill would not have leapt onto the presidential limousine. But they do.
} 
seen, there were many events between 22 and 29 November 1963 that can be used to retrodict that someone killed Kennedy on 22 November, and this is enough to get the negation of the consequent of the counterfactual (7). The reason for this unwelcome finding may just be that the negation of the antecedent of (7) is an indirect rather than a direct cause of the negation of its consequent.

Spohn might concede that the point made is a valid one and that his interpretation of counterfactuals must be amended. Indeed the amendment seems quite obvious. The idea would be that counterfactuals represent causal relations in general, not only direct relations between causes and effects. Following in the footsteps of Lewis (1973a, 2004), Spohn (2012, pp. 412-435) has argued vigorously that causation ought to be conceived of as a transitive relation. Indeed he defines causation to be the transitive closure of direct causation. Causation consists in chains of direct causation.

If Spohn is right that »most counterfactuals are to be interpreted in a causal way« (p. 1098/20), the natural way to proceed is just to make explicit that counterfactuals are to be interpreted in a directly or indirectly causal way. So while our objection in the last section obliterates the analysis of counterfactuals in terms of (4) and (5), it seems that something more complex remains valid. A natural suggestion would be to extend the counterfactual relation expressed in (4) and (5) by admitting chains of this very relation. What is expressed by the counterfactual (7) would then be this:

(8) there is a chain of propositions $A_{0}, A_{1}, \ldots, A_{n}$ such that $A_{0}=\overline{O_{t}}, A_{n}=\overline{W_{t^{\prime}}}$, and for every $i=1, \ldots, n, \tau\left(H_{i}^{*}\right)>0$ and $\tau\left(A_{i} \mid A_{i-1} \cap H_{i}^{*}\right)>0$, where

$$
H_{i}^{*}=\left\{w \in W: \tau\left(A_{i} \mid A_{i-1} \cap H_{w, t_{i}}^{t_{i-1}}>0\right\}\right.
$$

The move from (4) and (5) to (8) simulates the corresponding move from direct to indirect causes in Spohn's theory of causation.

Unfortunately this reply is not without problems either. First, (8) appears to be too complex to claim psychological reality as the thing we mean when we utter the counterfactual (7). Second, the problem that we discovered above in the relation between $\overline{O_{t}}$ and $\overline{W_{t^{\prime}}}$ might very well reappear between any neighbouring propositions $A_{i-1}$ and $A_{i}$ in the chain. In a model with discrete time, this problem can probably be avoided by employing very many $A_{i}$ 's, and in the limit by requiring that $A_{i-1}$ immediately precede $A_{i}$ for every $i=1, \ldots, n{ }^{19}$ But it is difficult to see how this problem can be avoided in continuous time where it does not make sense to speak of »the next point in time « 20 Third, and most importantly, if it were true that counterfactuals express chaining conditions of the form of (8), then they could not fail to be transitive. But ever since the work of Stalnaker (1968, p. 106) and Lewis (1973b, pp. 32-33), transitivity has been taken to be an inference scheme that is characteristically fallacious for counterfactuals ${ }^{21}$ A good structural paradigm for counterexamples against the transitivity of

\footnotetext{
${ }^{19}$ This requirement is discussed in Spohn 1983 p. 389) and called temporal immediacy of direct causation in Spohn (2012 p. 458).

${ }^{20}$ This problem is acknowledged in Spohn (1983, footnote 42), where he says that $\gg$ the relation of being a direct cause is likely to be empty or to be confined to simultaneous instantaneous propositions « in continuous time, and again in Spohn (2012 p. 358): »Realistically, one might say, time is continuous, and in continuous time there are no direct causes. «After the latter passage, Spohn suggests that »we should try to approximate [continuous time] by ever more fine-grained discrete time«.

${ }^{21}$ Transitivity for indicatives was challenged even earlier by Adams (1965. pp. 166-168).
} 
counterfactuals is provided by the workings of an electrical fuse or similar kinds of safety precautions. For instance, it is evident that from the premises

If Hinckley had not fired at Reagan, agent McCarthy would not have thrown himself in front of Reagan.

and

If agent McCarthy had not thrown himself in front of Reagan, Reagan would not have survived March 30, 1981.

it does not follow that

If Hinckley had not fired at Reagan, Reagan would not have survived March 30, 1981.

As an aside, we note that the factual connective because fails to be transitive in exactly the same way, at least if it represents a particular sort of causal relation. It is evident that from the premises

Because Hinckley fired at Reagan, agent McCarthy threw himself in front of Reagan.

and

Because Agent McCarthy threw himself in front of Reagan, Reagan survived March 30, 1981.

it does not follow that

Because Hinckley fired at Reagan, Reagan survived March 30, 1981.

Lewis (2004, pp. 96-99) lists a number of similar cases under the name »BlackRed counterexamples«; Spohn (2012, p. 431) mentions one such example that is due to Hall. Both Lewis and Spohn deny that these examples are counterexamples against the transitivity of causation. But I take such examples to establish beyond doubt that transitivity is characteristically invalid for the natural language connective because. Since because is paradigmatically used to represent the relevant sort of causal relation, transitivity should not be an axiom of a system called »a logic for because « (pace Schnieder 2011).

We conclude this section by noting that our attempt of transferring the strategy of Spohn's theory of causation to the analysis of counterfactuals and applying condition (8) in order to solve the most serious problem we identified with Spohn's conditions (4) and (5) has not been successful.

\section{Conclusion}

According to Spohn, a subjunctive conditional represents a proposition. A possible world belongs to this proposition if it is such that the consequent is believed, conditional on the antecedent and the (known or unknown) history of the consequent at this world, excluding the events at the antecedent time. That one has to conditionalise on this particular bit of history is a feature that Spohn takes over from his earlier definition of direct causes. But causal counterfactuals are frequently concerned with causes 
that are indirect, so the intermediate concept of direct causation does not suffice. Our discussion has indicated that we should not constrain the hypothesised, counterfactual course of events by a condition that includes (the agent's evidence about) the actual consequences of the actual happenings at the time of the antecedent. The strategy of taking the transitive closure that Spohn has employed in his theory of causation is not adequate for the interpretation of counterfactuals. Like the factual because, the counterfactual if ... then does not satisfy transitivity.

The situation presents us with a dilemma. Either we stick to the theory of counterfactuals as developed in Spohn $(2013 ; 2015)$. Then we get wrong predictions for many ordinary causal conditionals. Or we amend Spohn's theory by including indirect causes, just analogously to how Spohn (2012) builds up his theory of causation. Then we are committed to the transitivity of counterfactuals, which is wrong, too. I do not know how else to revise Spohn's analysis of counterfactuals in a way that remains close to his intentions, i.e., in a non-circular, reductive way that avoids recourse to causal concepts.

This is not the place to develop an alternative account of indicative and subjunctive conditionals at any length, but I want to suggest that the difference between the standard readings of indicative and subjunctive conditionals should run roughly along the following lines ${ }^{22}$

In evaluating the acceptability of an indicative conditional, the agent hypothetically adds the supposed antecedent event $A$ to her beliefs. Then she is allowed to change her beliefs about the actual course of events as much as is required for making the assumption of $A$ coherent with her beliefs. These changes are restricted in that the agent must respect all the evidence that she possesses about the actual course of events. She thus constructs a set of most plausible or probable hypothetical trajectories of facts. The end point of these trajectories must stay as close as possible to the agent's beliefs about the current state of the actual world. In short, indicative conditionals are total evidence conditionals.

In evaluating the acceptability of a subjunctive conditional, the agent hypothetically adds the supposed antecedent event $A$ to her beliefs. Then she goes back mentally to the time $t$ of the supposed antecedent event $A$ and makes minor adjustments of her beliefs about the past of $t$, so that she can assume that the event $A$ has happened as smoothly as possible ${ }^{23}$ After this change has been carried out, the agent is rather free to change her beliefs about the actual course of events after $t$. She may wilfully depart from the course of events in the actual world and use her imagination in order to explore hypothetically what would have happened as a consequence of $A$, unrestricted by any evidence she may possess about the actual events in the (presumed) causal cone of the negated antecedent event, i.e., about the actual events that are (considered to be) causally dependent on the negated antecedent event. She constructs the most plausible

\footnotetext{
${ }^{22} \mathrm{An}$ early and not fully correct formulation of this idea is given in Rott (2003). It should be possible, I think, to represent it formally in a framework of branching-time semantics in the style of McCall (1983. 1996 in particular pp. 163-191). I am afraid that the following sketch gives neither a non-circular nor an original account of counterfactuals.

${ }^{23}$ As already mentioned (see the fourth problem above), subjunctive conditionals usually need some backtracking in order to make the departure from the actual course of events a smooth one. The point of deviation (»the fork «, as Edgington 2004 p. 13, calls it) is located at some rather short time before $t$, but it need not lie immediately before $t$.
} 
or probable hypothetical trajectories of facts that coincide with the (presumed) past up to the point of deviation at some rather short time before $t$, using for her temporal extrapolation the laws of nature and assumptions about »the normal course of events « while respecting the circumstances between $t$ and $t^{\prime}$ that happened to have come about independently of the negated antecedent event. The end point of these trajectories may well deviate dramatically from the agent's beliefs about the current state of the actual world. In short, subjunctive conditionals are deviation conditionals.

If this picture is correct, then whatever evidence the agent might have about the events having happened after the antecedent time $t$ is relevant for the evaluation of indicatives. This is compatible with Spohn's approach, even though his condition (3) for indicatives does not mention any history at all. I think he assumes that the ranking function representing the agent's doxastic state, taken together with the method of conditionalisation (which is used for the evaluation of indicatives), guarantee that the strength of the evidence about the actual history one possesses will be suitably respected ${ }^{24}$ For the evaluation of subjunctives, though, whatever evidence the agent might have about the events having happened in the presumed causal cone of the negated antecedent event may and indeed must be disregarded.

A hypothetical trajectory in which no one killed Kennedy on 22 November 1963, or in which the Warren Commission was not established on 29 November 1963, is a very remote possibility with respect to any doxastic state that respects all the evidence an informed person possesses about the history of the actual world (or just the evidence she has about the history of the actual world up to and including 29 November 1963) — even after she has subtracted the evidence about what happened at 12:30 p.m. on 22 November 1963, and assumes that Oswald did not kill Kennedy. In contrast, such a trajectory is a close and natural one (for a Warrenite) if her doxastic state is modified by the hypothetical assumption that Oswald did not kill Kennedy at 12:30 p.m. on 22 November 1963, in such a way that she does not in the least respect her evidence about the events that (she takes to) have happened as causal consequences of the assassination 25

All of this, however, is quite speculative and should be subjected to further testing in realistic cases. The tragic assassination of John F. Kennedy has of course not only been used as a vehicle for developing and testing philosophical theories of conditionals, but has also been the topic of an immense number of works by contemporary historians and other writers. In the last two decades several authors tried to make substantive statements about what would or might have happened if Kennedy had not

\footnotetext{
${ }^{24}$ Let $E$ represent the conjunction of all »hard« evidence that the agent is completely certain of and is willing to maintain even if it turned out that $O$ is not true. It may perhaps be a good idea to join $E$ conjunctively with $\bar{O}$ in the condition in (3), so that we get something like $\tau(S \mid \bar{O} \cap E)>0$. The temporal location of the conjuncts of $E$ does not matter for indicatives.

${ }^{25}$ This account explains why in many cases, a subjunctive conditional gives a $»$ retrospective assessment « of an indicative conditional in cases in which we possess no evidence about events in the causal cone or the negated antecedent event. Cf. Edgington (2004, p. 16) on retrospective would conditionals and their corresponding earlier forward-looking will conditionals, or Edgington (2008, pp. 16-17; 2011 pp. 238-239) on the potential of any indicative conditional to be transformed into a counterfactual conditional, provided the context is suitable. It also explains why indicatives and subjunctives with antecedent events in the future are more or less synonymous. Both of these explananda strike me as strong reasons to strive for a uniform analysis of indicatives and subjunctives, and I think the idea just sketched is as uniform an account as Spohn's.
} 
been killed in November 1963. In fact this has become one of the major exercise areas for counterfactual history ${ }^{26}$ Philosophers should be able to sharpen their wits on the whetstone of real-life scenarios like this one.

\section{Acknowledgements}

For the reasons described at the beginning of this paper, my greatest debt here is to Wolfgang Spohn. Thank you very much, Wolfgang! I am also grateful to John Cantwell, Paul Égré, Arthur Paul Pedersen, Stefan Ruhland, Christopher von Bülow and Alexandra Zinke for their valuable comments. Last but not least, I thank the University of Regensburg and the Swedish Collegium of Advanced Study in Uppsala for providing me with excellent research conditions while I was preparing this paper.

\section{References}

Adams, E. W. (1965). The logic of conditionals. Inquiry, 8, 166-197.

Adams, E. W. (1970). Subjunctive and indicative conditionals. Foundations of Language, 6(1), 89-94.

Bennett, J. (2003). A philosophical guide to conditionals. Oxford: Oxford University Press.

Berman, L. (1997). NSAM 263 and 273: Manipulating history. In L. C. Gardner and T. Gittinger (eds.), Vietnam: The early decisions (pp. 177-203). Austin, TX: University of Texas Press.

Blight, J. G., Lang, J. M., and Welch, D. A. (2010). Virtual JFK: Vietnam if Kennedy had lived. Lanham, MD: Rowman and Littlefield.

Dallek, R. (2003). JFK lives. In R. Cowley (ed.), What ifs? of American history: Eminent historians imagine what might have been (pp. 273-284). New York: G.P. Putnam's Sons.

Douglass, J. W. (2008). JFK and the Unspeakable: Why he died and why it matters. Maryknoll, NY: Orbis Books.

Dubois, D., and Prade, H. (1991). Epistemic entrenchment and possibilistic logic. Artificial Intelligence, 50, 223-239.

Edgington, D. (1995). On conditionals. Mind, 104, 235-329.

Edgington, D. (2004). Counterfactuals and the benefit of hindsight. In P. Dowe and P. Noordhof (eds.), Cause and chance: Causation in an indeterministic world (pp. 12-27). London: Routledge.

Edgington, D. (2008). Counterfactuals. Proceedings of the Aristotelian Society, 108, $1-21$.

Edgington, D. (2011). Causation first: Why causation is prior to counterfactuals. In C. Hoerl, T. McCormack, and S. R. Beck (eds.), Understanding counterfactuals, understanding causation: Issues in philosophy and psychology (pp. 230-241). Oxford: Oxford University Press.

Gillies, A. S. (2012). Indicative conditionals. In G. Russell and D. G. Fara (eds.), Routledge companion to philosophy of language (pp. 449-465). New York: Routledge.

${ }^{26}$ See Berman (1997), Kunz (1997), Logevall (1998), Dallek (2003), Blight, Lang and Welch (2010) and Greenfield (2013). Of particular interest to such work has been the potential cutback of the United States' involvement in Vietnam. 
Goldszmidt, M., and Pearl, J. (1992). Rank-based systems: A simple approach to belief revision, belief update, and reasoning about evidence and actions. In Proceedings of the third international conference on principles of knowledge representation and reasoning (KR'92) (pp. 661-672). Cambridge, MA: Morgan Kaufmann.

Goodman, N. (1954). Fact, fiction, and forecast. London: Athlone Press.

Greenfield, J. (2013). If Kennedy lived: The first and second terms of President John F. Kennedy: An alternate history. G.P. Putnam's Sons.

Hume, D. (1756). Enquiry concerning human understanding (third ed.). London: A. Millar.

Iatridou, S. (1994). Contribution of conditional then. Natural Language Semantics, 2 , 171-199.

Kunz, D. (1997). Camelot continued: What if John F. Kennedy had lived? In N. Ferguson (ed.), Virtual history: Alternatives and counterfactuals (pp. 368-391). London: Picador.

Lewis, D. (1973a). Causation. Journal of Philosophy, 70(17), 556-567.

Lewis, D. (1973b). Counterfactuals. Oxford: Blackwell.

Lewis, D. (2004). Causation as influence. In J. Collins, N. Hall, and L. A. Paul (eds.), Causation and counterfactuals (pp. 75-117). Cambridge, MA: MIT Press.

Logevall, F. (1998). Vietnam and the question of what might have been. In M. J. White (ed.), Kennedy: The new frontier revisited (pp. 19-62). New York: New York University Press.

McCall, S. (1983). If, since and because: A study in conditional connection. Logique et Analyse, 26(103-104), 309-321.

McCall, S. (1996). A model of the universe: Space-time, probability, and decision. Oxford: Oxford University Press.

McKnight, G. D. (2005). Breach of trust: How the Warren Commission failed the nation and why. Lawrence, KS: University Press of Kansas.

Reichenbach, H. (1954). Nomological statements and admissible operations. Amsterdam: North Holland.

Rott, H. (1986). Ifs, though and because. Erkenntnis, 25(3), 345-370.

Rott, H. (2003). Variably restricted necessity: Truth and fiction in the interpretation of indicative and subjunctive conditionals. In H. Rott and V. Horák (eds.), Possibility and reality: Metaphysics and logic (pp. 269-296). Frankfurt a.M.: Ontos.

Rott, H. (2014). Unvergleichbarkeit und unabhängige Bedeutung (Comments on Wolfgang Spohn's The Laws of Belief). Zeitschrift für philosophische Forschung, 68, 237-241.

Ryle, G. (1950). "If," “so," and "because”. In M. Black (ed.), Philosophical analysis (pp. 323-340). Ithaca, NY: Cornell University Press.

Schnieder, B. (2011). A logic for 'because'. Review of Symbolic Logic, 4, 445-465.

Spohn, W. (1983). Deterministic and probabilistic reasons and causes. Erkenntnis, 19(1), 371-396. (Special issue Methodology, Epistemology, and Philosophy of Science. Essays in Honour of Wolfgang Stegmüller on the Occasion of His 60th Birthday, eds. C. G. Hempel, H. Putnam and W. K. Essler.)

Spohn, W. (1988). Ordinal conditional functions: A dynamic theory of epistemic states. In W. Harper and B. Skyrms (eds.), Causation in decision, belief change, and statistics (pp. 105-134). Dordrecht: Kluwer.

Spohn, W. (2012). The laws of belief. Oxford: Oxford University Press. 
Spohn, W. (2013). A ranking-theoretic approach to conditionals. Cognitive Science, 37, 1074-1106.

Spohn, W. (2015). Conditionals: A unifying ranking-theoretic perspective. Philosophers' Imprint, 15(1), 1-30.

Stalnaker, R. (1968). A theory of conditionals. In N. Rescher (ed.), Studies in logical theory (Vol. 2, pp. 98-112). Oxford: Blackwell.

Stalnaker, R. (1975). Indicative conditionals. Philosophia, 5(3), 269-286.

von Fintel, K. (2012). Subjunctive conditionals. In G. Russell and D. G. Fara (eds.), Routledge companion to philosophy of language (pp. 466-477). New York: Routledge. 